Available online at www.eccomasproceedia.org

Eccomas Proceedia COMPDYN (2021) 4481-4493

ECCOMAS

Proceedia
COMPDYN 2021

$8^{\text {th }}$ ECCOMAS Thematic Conference on

Computational Methods in Structural Dynamics and Earthquake Engineering M. Papadrakakis, M. Fragiadakis (eds.) Streamed from Athens, Greece, 28 - 30 June 2021

\title{
COMPARISON OF CONTROL ALGORITHMS APPLIED TO AN HYBRID MASS DAMPER ATTACHED TO A WIND TURBINE TOWER
}

\author{
Pedro H. Q. Rocha ${ }^{1}$, Suzana M. Avila ${ }^{1}$ \\ ${ }^{1} \mathrm{PPG}$ - Integrity of Engineering Materials, University of Brasília Área Especial Indústria and Projeção \\ A - UnB, 72.444-240, DF/Gama, Brasil \\ e-mail: rochapedroeng@gmail.com, avilas@unb.br
}

\begin{abstract}
The structural control, basically, promotes a change in the damping and stiffness properties of the structure, either by the addition of external devices or by the action of external forces. It can be classified as: passive control, active control, hybrid control or semi-active control (Soong \& Dargush, 1997). The hybrid mass damper (HMD) is a system that deals with the combination of a tuned mass damper (TMD) with an active control actuator. In addition to requiring lower control forces and maintaining its efficiency over a long range of frequencies, this system has a more robust and reliable control, when compared to active and passive alone (Collette \& Chesné, 2016). Among the structures, the wind turbine stands out, which is supported by towers, which due to its geometry and height, are slender, flexible and can suffer excessive levels of vibration caused by the operation of the turbine, as well as by external forces (Woude \& Narasimhan, 2014). In this work it is proposed the application of a structural control system, in the way of HMD, to protect a wind tower with theoretical dimensions and with a simplified as single degree of freedom model, submitted to wind and seismic loads that leads to levels of undesirable vibrations that may compromise the safety and integrity of the structure. In addition, it is proposed to compare the performances obtained from the system without control and by the Instantaneous Optimal Control (IOC), Proportional Integral Derivative (PID) and Linear Quadratic Regulator (LQR) controllers with numerical simulations performed using the MAPLESOFT, MATLAB and its Simulink control toolbox. The results obtained numerically were analyzed and compared with each other, and it was observed that $H M D$ was efficient in reducing the dynamic response of the tower. Although it is a preliminary model, it is a basis for studies in this area to evolve into a more sophisticated model and fullscale applications.
\end{abstract}

Keywords: Hybrid mass damper; Wind Turbine; Seismic; Instantaneous Optimal Control; Proportional Integral Derivative; Linear Quadratic Regulator.

ISSN:2623-3347 C 2021 The Authors. Published by Eccomas Proceedia.

Peer-review under responsibility of the organizing committee of COMPDYN 2021.

doi: 10.7712/120121.8801.19054 


\section{INTRODUCTION}

According to GWEC [1], despite being a pandemic year, 2020 was a record year of wind growth with an estimated $82.3 \mathrm{GW}$ of new wind energy capacity globally, according to initial calculations by GWEC, which represents an increase of $36 \%$ in installations.

This expansive growth on energy generation is reflected to technological development, as well as in the development of increasingly tall and slender wind turbines, and as a consequence, these turbines can suffer severe dynamic excitations, thus reaching the service limit state for excessive vibrations $[2,3]$.

One way to reduce excessive vibration levels, maintain the stability and safety of systems and avoid collapse is to use the structural control solution, which can be classified into four categories, such as passive, active, hybrid and semi-active control. These four categories are based on applying external corrective forces or on the installation of external devices in order to reduce the levels of vibrations experienced by the structures and/or promoting variations in stiffness and damping properties of the main structure [4].

Each structural control category has a specific characteristic and can have more than one control method. The hybrid control has characteristics of passive control added to active control ones, always with the aim of increasing the performance of the system when compared, with a purely passive control. Making also the system less dependent on energy, when compared with the active control alone. The hybrid control uses actuators and energy dissipators [5].

According to Bhaiya [6] and $\mathrm{Hu}$ and $\mathrm{He}$ [7], the hybrid controller has a wider frequency range than the passive controller, making it more efficient and requiring less force than the active one, which reduces the cost of the system. In the case of a power failure or failure of the active control component, the passive component of the hybrid control still offers some level of protection The hybrid mass damper (HMD) is the combination of a tuned mass damper (TMD) with an active control actuator [8,9].

S. Xie, X. Jin, J. He et al. [10] developed a numerical model of a reduced-order offshore wind turbine, subjected to wind loads, sea waves and earthquakes for hybrid control. The authors found that the HMD system can better reduce the displacement from the top of the tower compared to the passive TMD system before and during earthquakes, although the need of high input control power and large displacements of the TMD.

D. Lima, P. López-Yánez and M. Pereira [11] presented a a vibration control device design for a 120-meter-high steel tubular tower for a wind turbine. Three types of absorbers were then studied comparatively: tuned mass damper (TMD), active mass damper (AMD) and hybrid mass damper (HMD). They used the Linear Quadratic Regulator (LQR) to obtain the optimal control variables introduced by the actuators hydraulic. It was found that the HMD achieves excellent levels of vibration reduction for the tower subjected to harmonic actions, in a transient and permanent (stationary) regime, resonant to the first mode of vibration of the structure without control.

M. Rahman, Z. Ong, Zhi Chao, W. Chong et al. [12] implements a proportional derivative integral controller (PID) designed and optimized to find the ideal required force for actuators and, therefore, reduce the vibration of the wind generator tower. The active vibration control system with an optimized PID controller in the wind turbine tower offered a higher rate of vibration reduction under different loads compared to the uncontrolled and passive control system.

Yanik [13] makes a comparison between the LQR controller and the Instantaneous Optimal Controller (IOC) using seismic forcing for a semi-active system applied in a 3storey building and a 5-storey building. 
In this work it is proposed the application of a structural control system, considering a HMD, to protect a wind tower with theoretical dimensions considering a simplified single degree of freedom model. It is submitted to wind and seismic loads that leads to levels of undesirable vibrations that may compromise the safety and reliability of the structure. In addition, it is proposed to compare the performances obtained from the system without control and with an HMD using different controllers: Instantaneous Optimal Control (IOC), Proportional Integral Derivative (PID) and Linear Quadratic Regulator (LQR)through numerical simulations.

\section{MATHEMATICAL FORMULATION}

The large wind turbine studied in this work is composed of a tall, slender and flexible tower that supports the blades and nacelle at the top. The system has infinite degrees of freedom, however, through a modal reduction technique, it is possible to model it as a discrete system with multiple degrees of freedom (MDOF) [14]. The effects of rotating the blades and their vibrations in the flapwise and edgewise directions are not considered in this preliminary model [2]. This structure can be modeled as a system having $\mathrm{N}$ degrees of freedom with a TMD device installed and subjected to external dynamic excitation [15]. Figure 1 represents the turbine and the system modelled as a cantilever beam with a tip mass.
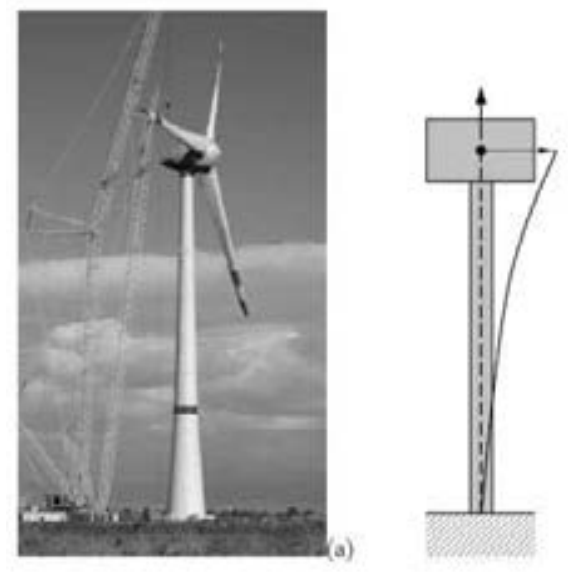

(b)

Figure 1. (a) Tubular structures of steel tower of wind turbines; (b) Schematic description of a cantilever beam with a tip mass [2].

In systems with multiple degrees of freedom, it is possible to reduce the structural response to a single degree of freedom and obtain the structural response for structural systems that vibrate mainly on a single mode, usually the first $[4,8,14]$.

Although the structural model of the wind turbine has multiple degrees of freedom, the system under study was reduced to a single degree of freedom [4] and a hybrid tuned mass damper was added to the top of the turbine, which is connected to the main system with the intention of decreasing the amplitude of the structure vibration $[2,4]$.

The main system representing a wind turbine, reduced to a single degree of freedom associated with an HMD, shown in Figure 2, has two degrees of freedom, where $\boldsymbol{M}_{1}$ is the mass, $\boldsymbol{K}_{1}$ is the stiffness and $\boldsymbol{C}_{1}$ is the damping of the main system, while $\boldsymbol{M}_{2}$ is the upper mass of HMD, $\boldsymbol{K}_{2}$ is the stiffness of HMD and $\boldsymbol{C}_{2}$ is the damping of HMD, $\boldsymbol{F}(t)$ is the dynamic load applied on the structure, $\boldsymbol{u}(t)$ is the control force, while $\boldsymbol{y}(t)$ and $\boldsymbol{z}(t)$ 
are the horizontal displacements of the main system and the HMD, respectively.

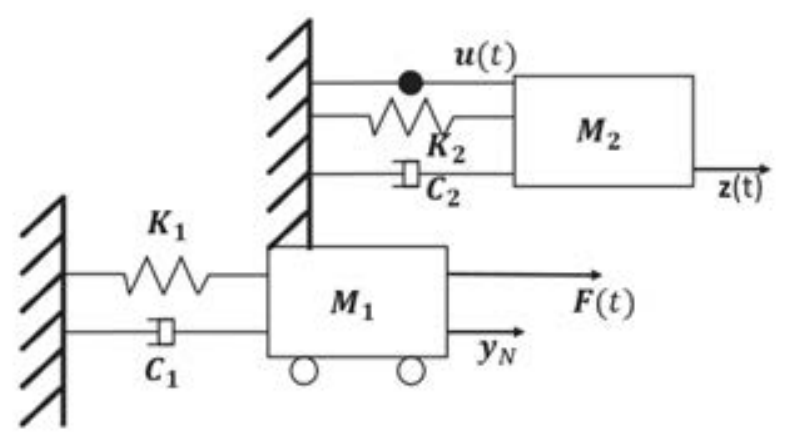

Figure 2. Two degrees of freedom model: main system + mass damper tuned with $\boldsymbol{u}(t)$ (HMD) actuator $[16]$.

The equations of motion of the main system with a connected HMD, including the force applied to the base of the structure $g(t)$, and control force $\boldsymbol{u}(t)$ is given by (2):

$$
\begin{gathered}
\boldsymbol{M}_{\mathbf{1}} \ddot{\boldsymbol{y}}(t)+\boldsymbol{C}_{\mathbf{1}} \dot{\boldsymbol{y}}(t)+\boldsymbol{K}_{\mathbf{1}} \boldsymbol{y}(t)=\boldsymbol{F} \\
\boldsymbol{M}_{\mathbf{2}} \ddot{\mathbf{z}}(t)+\boldsymbol{C}_{\mathbf{2}} \dot{\boldsymbol{z}}(t)+\boldsymbol{K}_{\mathbf{2}} \boldsymbol{z}(t)=-\boldsymbol{M}_{\mathbf{2}} \ddot{\boldsymbol{y}}(t)+g(t)+\boldsymbol{u}(t)
\end{gathered}
$$

Three control algorithms were used to calculate the control force $\boldsymbol{u}(t)$ in order to compare their performances: Linear Quadratic Regulator (LQR), Proportional, Integral, Derivative (PID) and Instantaneous Optimal Control (IOC). The Optimal Control aims to control the dynamic system at a minimum cost, the optimization process is performed through the Linear Quadratic Regulator (LQR). The LQR can be presented as a regulator that stabilizes the system's response. It is a controller capable of optimizing through control considering the constraints of a cost function and uses all states of the system for feedback, while the gain of control is selected in a way that the performance index subjected to the constraints of the system state equation is minimized [17, 18]. Although the LQR controller deals better with systems with multiple inputs and multiple outputs, on the other hand it has certain difficulties in defining the cost function and the weighting matrices $[19,20]$.

For modeling the LQR controller, it is necessary to represent the equations of motion of the system in state space form, according to the state equation (3) and the output equation (4) for $n$ degrees of freedom.

Where $\boldsymbol{A}$ is the state matrix, $\boldsymbol{B}$ is the input matrix, $\boldsymbol{C}$ is the output matrix and $\boldsymbol{D}$ is the direct transmission matrix. Equations (5) and (6) represent the equations of motion of the system under study in this work in the state space.

$$
\begin{gathered}
\dot{\boldsymbol{x}}(t)=\boldsymbol{A} \boldsymbol{x}(t)+\boldsymbol{B u}(t) \\
\boldsymbol{y}(t)=\boldsymbol{C} \boldsymbol{x}(t)+D \boldsymbol{u}(t) \\
{\left[\begin{array}{c}
\dot{\boldsymbol{X}}_{1} \\
\dot{\boldsymbol{X}}_{2}
\end{array}\right]=\left[\begin{array}{cc}
0 & \boldsymbol{I} \\
-\boldsymbol{M}^{-\mathbf{1}} \boldsymbol{K} & -\boldsymbol{M}^{-\mathbf{1}} \boldsymbol{C}
\end{array}\right\rceil\left[\begin{array}{l}
\boldsymbol{X}_{1} \\
\boldsymbol{X}_{2}
\end{array}\right]+\left[\begin{array}{c}
0 \\
\boldsymbol{M}^{-1}
\end{array}\right] \boldsymbol{u}} \\
\boldsymbol{Y}=\left[\begin{array}{llll}
1 & 0 & 0 & 0
\end{array}\right\rceil\left[\begin{array}{l}
\boldsymbol{X}_{1} \\
\boldsymbol{X}_{2}
\end{array}\right]+\left[\begin{array}{l}
0 \\
0
\end{array}\right]
\end{gathered}
$$


For structural control, the classical optimal control problem consists in finding the control vector $\boldsymbol{u}(t)$ that minimizes the quadratic performance index [21]:

$$
\boldsymbol{J}=\int_{t_{0}}^{t_{f}}\left[\boldsymbol{x}^{\boldsymbol{T}}(t) \boldsymbol{Q} \boldsymbol{x}(t)+\boldsymbol{u}^{\boldsymbol{T}}(t) \boldsymbol{R} \boldsymbol{u}(t)\right] d t
$$

where $\boldsymbol{Q}$ is a real, symmetrical and positive semi-defined $2 n \times 2 n$ real, matrix and $\boldsymbol{R}$ is a real, symmetric and positive defined $m \times m$ matrix. The matrices $\boldsymbol{Q}$ and $\boldsymbol{R}$ are weighting matrices, whose magnitudes are defined according to the relative importance given to the state variables and the control forces in the minimization process.

According to Meirovitch [21], in structural applications, the Riccati matrix, $\boldsymbol{P}(t)$ can be approximated by a constant matrix $\boldsymbol{P}$. The minimization of the index falls on the solution of the Riccati equation.

$$
P A-\frac{1}{2} P B R^{-1} B^{T} P+A^{T} P+2 Q=0
$$

Having knowledge of the weighting matrices $\boldsymbol{Q}$ and $\boldsymbol{R}$, it is possible to obtain the control gain, that is $\boldsymbol{G}$ given by

$$
G=-\frac{1}{2} R^{-1} B^{T} P
$$

The optimal control law establishes a linear relationship of the control vector $\boldsymbol{u}(t)$.

$$
\boldsymbol{u}(t)=\boldsymbol{G} \boldsymbol{x}(t)=-\frac{1}{2} \boldsymbol{R}^{-1} \boldsymbol{B}^{\boldsymbol{T}} \boldsymbol{P} \boldsymbol{x}(t)
$$

When $\boldsymbol{x}(t)$ is known, $\boldsymbol{u}(t)$ can be obtained through equation (10) generating a closed loop system. $\boldsymbol{H} \boldsymbol{f}(t)$ is the portion related to external loading. The behavior of the optimally controlled structure is described by

$$
\begin{aligned}
\dot{\boldsymbol{x}}(t) & =\boldsymbol{A} \boldsymbol{x}(t)+\boldsymbol{B u}(t)+\boldsymbol{H} \boldsymbol{f}(t) \\
\dot{\boldsymbol{x}}(t) & =(\boldsymbol{A}+\boldsymbol{B} \boldsymbol{G}) \boldsymbol{x}(t)+\boldsymbol{H} \boldsymbol{f}(t)
\end{aligned}
$$

It can be seen that the effect of closed loop control is to change the state matrix of the system from $\boldsymbol{A}$ (open loop system) to $\boldsymbol{A}+\boldsymbol{B} \boldsymbol{G}$ (closed loop system).

Another controller used in the comparison of the present work was the Proportional Integral Derivative (PID), this controller features the use of closed loop control loop feedback to keep the actual output of a process as close as possible to the destination output or setpoint [19].

The MATLAB control system's Simulink toolbox provides algorithms and applications for systematically analyze, design and adjust linear control systems. It is possible to specify a system as a transfer function, status space, zero pole gain or frequency response model.

The response of the PID controller was calculated using Simulink using the closed loop block diagram with the insertion of external forces such as wind and earthquake. 
The transfer function of the system in relation to the HMD installed on top of the wind turbine, presents the ratio between the displacement of the main system (output) and the control force (input). Figure 3 represents a block diagram of Simulink with PID control under the action of external forces.

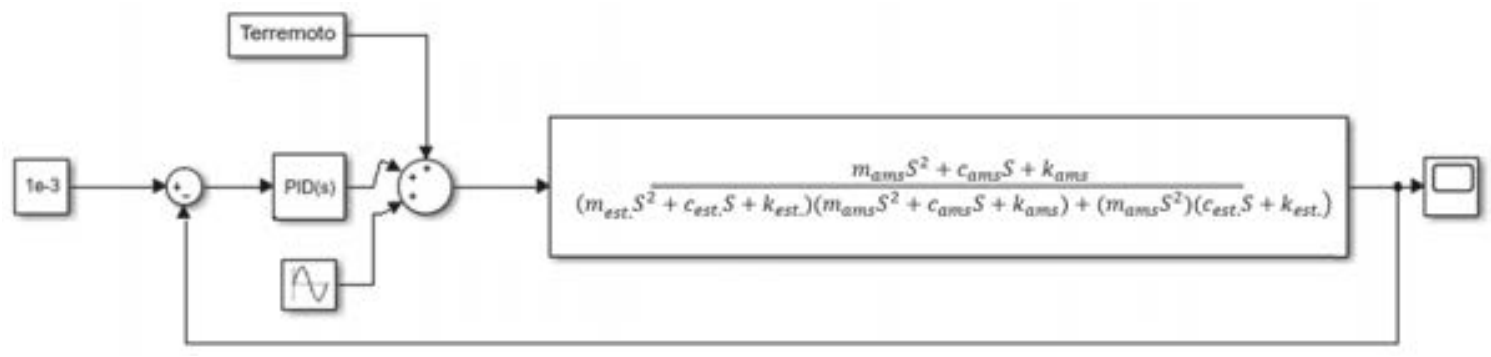

Figure 3. Closed loop block diagram with PID [16].

The instantaneous optimal control (IOC) is a variation of the classic optimal control aiming at computational cost savings since it does not require the solution of the Riccati equations [20]. For this controller, the same formulation of the equations of motion of the system was used in the form of state equations of state shown previously eq. (3) and eq. (4). This algorithm is easier to implement, since it is not necessary to calculate the Riccati matrix [8].

The quadratic performance index, represented by eq. (13), is minimized in each instant of time,

$$
\boldsymbol{J}(t)=\boldsymbol{x}^{T}(t) \boldsymbol{Q} \boldsymbol{x}(t)+\boldsymbol{u}^{T}(t) \boldsymbol{R} \boldsymbol{u}(t)
$$

where $\boldsymbol{T}$ is the modal matrix, whose columns are the eigenvectors of $\boldsymbol{A}$.

$$
\boldsymbol{x}(t)=\boldsymbol{T} \boldsymbol{w}(t)
$$

From the decoupled state equations, the diagonal matrix with the eigenvalues of $\boldsymbol{A}$ is obtained.

$$
\bigwedge=T^{-1} A T
$$

Over a short time step $\Delta t$, the modal state vector $\boldsymbol{x}(t)$ can be expressed as

$$
d(t-\Delta t)=\exp (\wedge \Delta t) \boldsymbol{T}^{-1}\left\{\boldsymbol{x}(t-\Delta t)+\frac{\Delta t}{2}[\boldsymbol{B} \boldsymbol{u}(t-\Delta t)+\boldsymbol{H} \boldsymbol{f}(t-\Delta t)]\right\}
$$

The weighting matrices $\boldsymbol{Q}$ and $\boldsymbol{R}$ are also arbitrarily defined in the IOC case, they influence the control force and the displacement suffered represented by equations (17) and (18), respectively.

$$
\begin{gathered}
\boldsymbol{u}(t)=-\frac{\Delta t}{2} \boldsymbol{R}^{-\mathbf{1}} \boldsymbol{B}^{\boldsymbol{T}} \boldsymbol{Q} \boldsymbol{x}(t) \\
\boldsymbol{x}(t)=\left[\boldsymbol{I}+\frac{\Delta t^{2}}{4} \boldsymbol{B} \boldsymbol{R}^{-1} \boldsymbol{B}^{\boldsymbol{T}} \boldsymbol{Q}\right]^{-1}\left[\boldsymbol{T} \boldsymbol{d}(t-\Delta t)+\frac{\Delta t}{2} \boldsymbol{H} \boldsymbol{f}(t)\right]
\end{gathered}
$$

The optimized control force was calculated according to the procedures used by S. 
Avila and P. Gonçalves [22].

\section{RESULTS}

In this, it is considered a wind turbine, previously studied by S. Avila, M. Shzu, M. Morais et al. [2]. The structure was reduced to a single degree of freedom model and subjected to the following loads: earthquake El Centro [23]; harmonic loading $f(t)=$ $2500 \operatorname{sen}(w t)$ applied at the top of the tower. The mass, damping and stiffness properties of the structure are, respectively, $\boldsymbol{M}_{\mathbf{1}}=34,899,00 \mathrm{~kg}, \boldsymbol{C}_{\mathbf{1}}=0,00 \mathrm{Ns} / \mathrm{m}$ and $\boldsymbol{K}_{\mathbf{1}}=$ 463,671,00 N/m. HMD properties were calculated using Den Hartog equations [24]: $\boldsymbol{M}_{\mathbf{2}}=967,98 \mathrm{~kg}, \boldsymbol{C}_{\mathbf{2}}=427,6724 \mathrm{Ns} / \mathrm{m}$ and $\boldsymbol{K}_{\mathbf{2}}=8,9096 \times 10^{3} \mathrm{~N} / \mathrm{m}$. The damping ratio, $\zeta$, is assumed to be $2 \%$ of the critical value.

Initially, the controller of the LQR type had the control force in the HMD actuator calculated and one of the factors that influence the achievement of good results through this algorithm is the choice of the weighting matrices $\boldsymbol{Q}$ and $\boldsymbol{R}$. The values of the coefficients of the weighting matrices $\boldsymbol{Q}$ and $\boldsymbol{R}$ are defined according to the relative importance given to state variables and control forces in the minimization process [21, 22]. The weighting matrices used in the analysis were as follows:

$$
\begin{aligned}
& \boldsymbol{Q}=\left[\begin{array}{cccc}
10^{10} & 0 & 0 & 0 \\
0 & 10^{2} & 0 & 0 \\
0 & 0 & 10^{2} & 0 \\
0 & 0 & 0 & 1
\end{array}\right] \\
& \boldsymbol{R}=[1]
\end{aligned}
$$

The LQR was performed using a function from the MATLAB library and still using a closed-loop block diagram using the Matlab Simulink toolbox. Figure 4 represents the block diagram of the LQR controller for the hybrid mass damper under the action of wind force (represented by the sinusoidal excitation) and seismic excitation (represented by the El Centro earthquake), where $\boldsymbol{A}$ is the state matrix, $\boldsymbol{B}$ is the input matrix, $\boldsymbol{C}$ is the output matrix and $G$ is the gain.

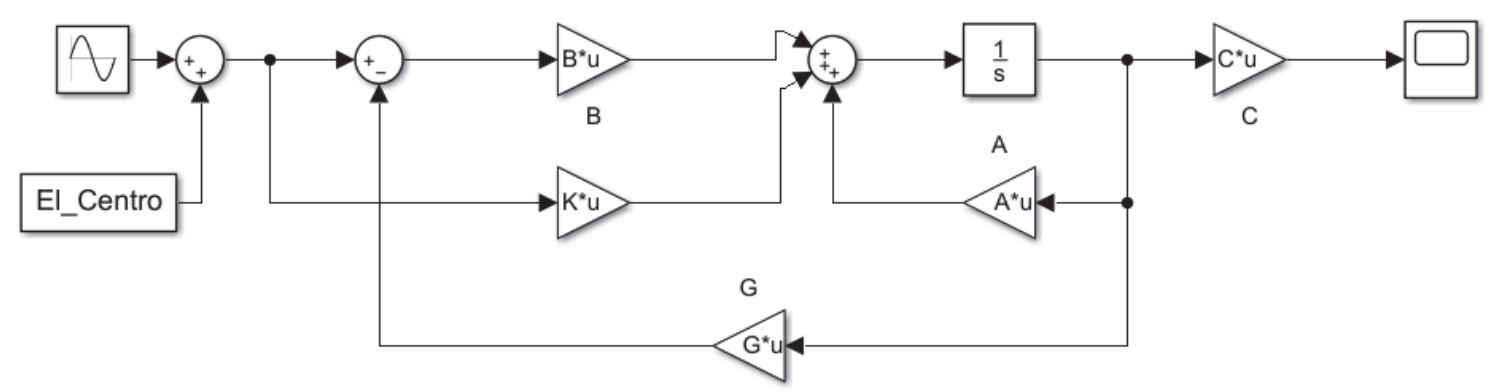

Figure 4. Block diagram of the LQR controller with HMD [16]. 
The displacement time history of the main structure is shown in Figure 5, comparing the use of a tuned mass damper (TMD) and an HMD, considering seismic and wind excitations with LQR controller. It can be seen that the HMD demonstrated an excellent performance, reducing, approximately, up to 6 times the amplitude of vibration presented with the passive control (TMD), when compared to the HMD.

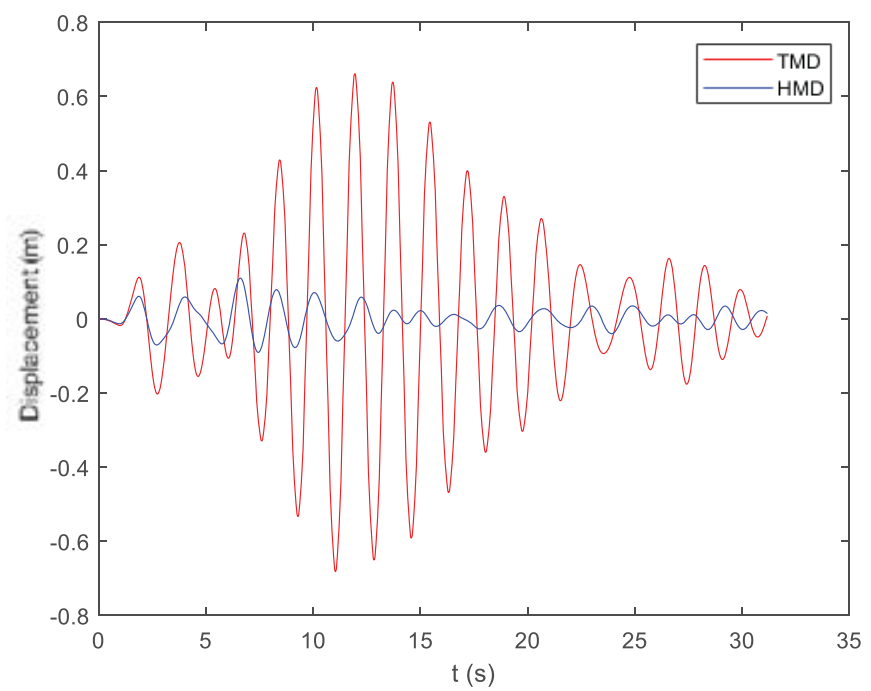

Figure 5. Time history displacement of the main system (comparative AMS x HMD) [16].

Then, numerical simulations are performed using the PID controller to obtain the HMD control force and the displacement of the main system [16]. The gains of the PID controller were obtained through the MATLAB computer package tuning tools and the Simulink toolbox. Figure 6 presents the block diagram for system analysis with HMD using the PID controller to calculate the control force. The system is subjected to the same wind and earthquake excitations, through the PID block and the transfer function of the hybrid system.

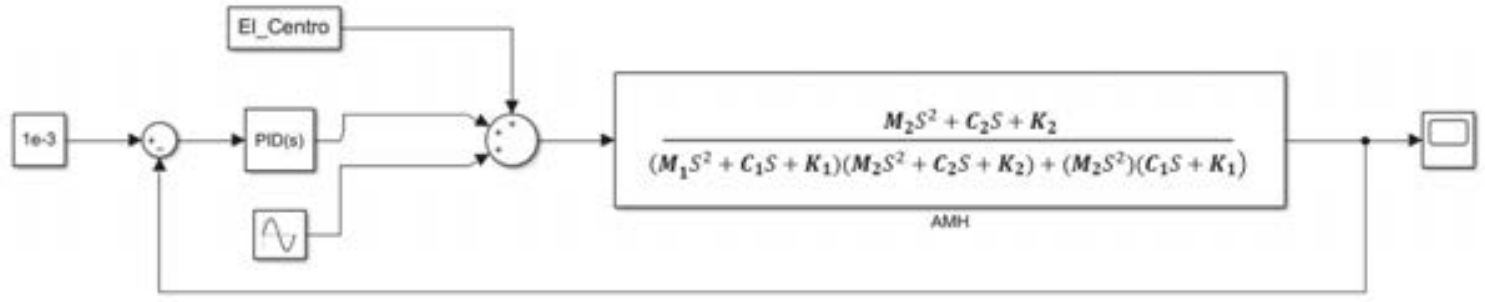

Figure 6. Block diagram of the PID controller with HMD [16].

Figure 7 shows the comparison of the response, in terms of the evolution of displacement, for the HMD, of the main system using the system without control and the LQR and PID controllers. It is possible to observe that the LQR controller has a better performance than the PID controller, with a reduction, compared to the uncontrolled system response, of approximately $63 \%$ and $43 \%$, respectively. 


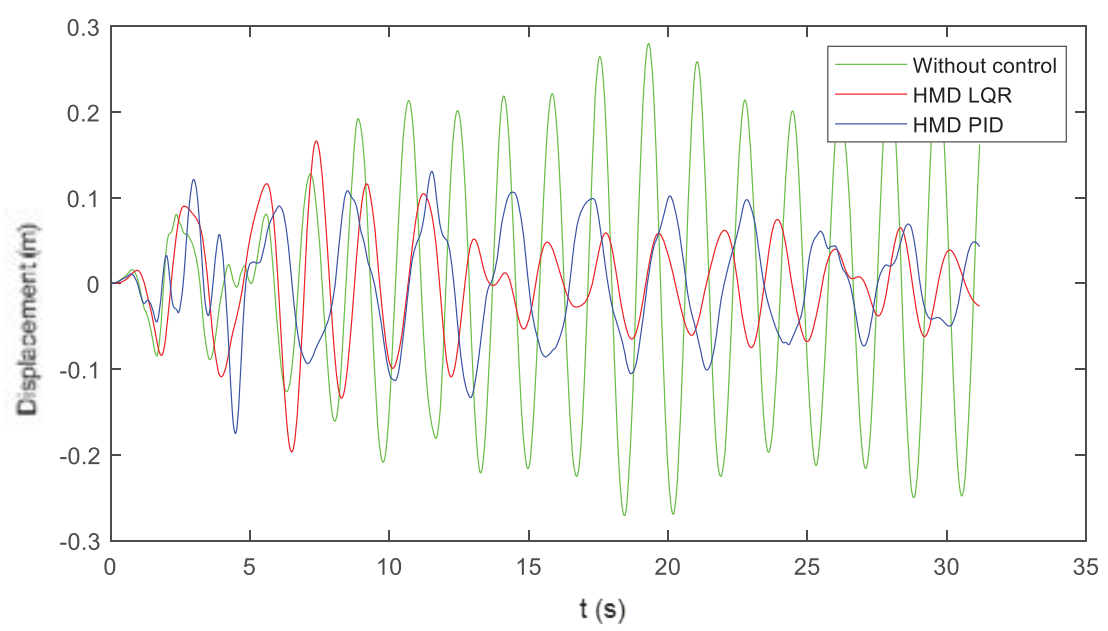

Figure 7. Time history displacement of the HMD using the LQR and PID controllers [16].

The rms displacement value, for the HMD, obtained for the system without control was $0.2098 \mathrm{~m}$, while for the system with LQR controller, the displacement was 0.04506 $\mathrm{m}$ and for the PID it was $0.09592 \mathrm{~m}$. For the LQR and PID controllers, there was a reduction in the rms response of approximately $78.5 \%$ and $54.2 \%$, respectively.

Figure 8 presents the comparison of the evolution in time of the control force required in the LQR and PID controllers, where the maximum required force is $28030 \mathrm{~N}$ and 2735 $\mathrm{N}$, respectively. It appears that the required control force, using the LQR, was approximately 10 times greater than the control force obtained with the PID controller.

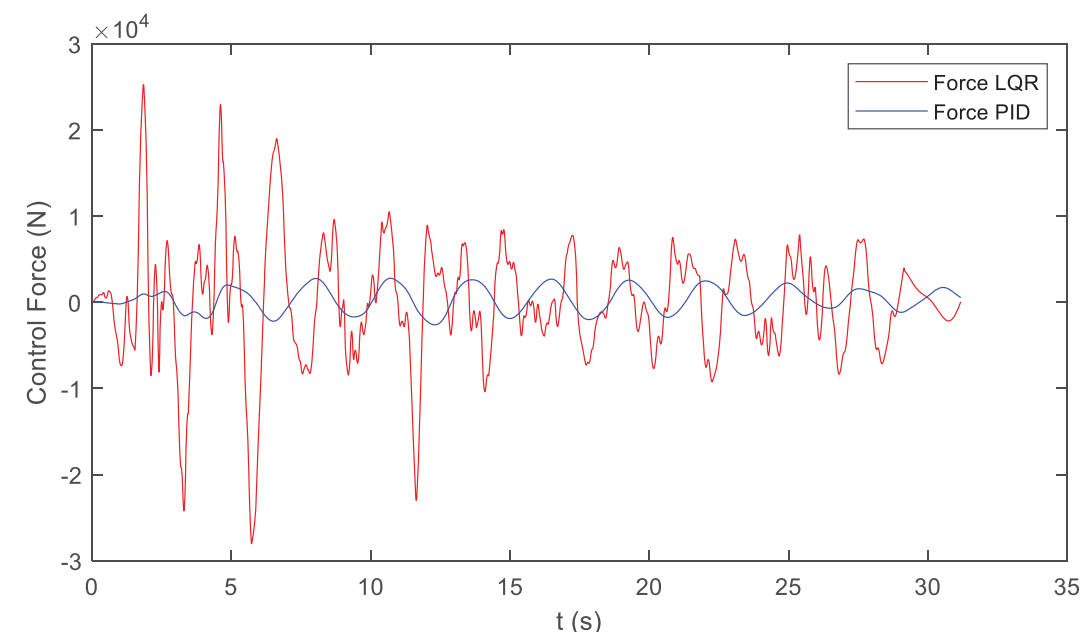

Figure 8. Time evolution of the control force required in the LQR and PID [16].

The IOC also needs an adjustment in the weighting matrices, where equations (21) and (22) present the matrices $\boldsymbol{Q}$ and $\boldsymbol{R}$, respectively.

$$
\begin{aligned}
& \boldsymbol{Q}=\left[\begin{array}{llll}
0 & 0 & 0 & 0 \\
0 & 0 & 0 & 0 \\
6.654 * 10^{3} & 0 & 0 & 0 \\
1 * 10^{-3} & 0 & 0 & 0
\end{array}\right] \\
& \boldsymbol{R}=[1000000]
\end{aligned}
$$


For the IOC algorithm, the calculations were performed using MATLAB, where it was possible to obtain the answer in a time range of $600 \mathrm{~s}$. Figure 9 shows the evolution in time of the displacement of the main structure controlled by an HMD with an IOC controller. It is possible to observe that the amplitude of the response has an order of magnitude ten times smaller than those obtained in the simulations with the LQR and PID controllers.

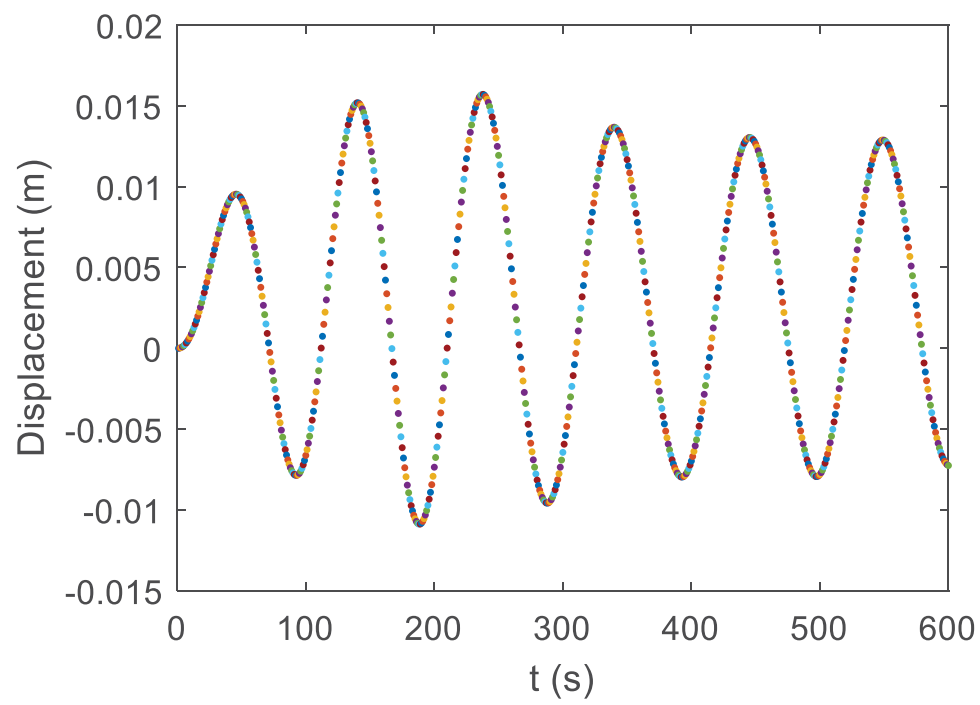

Figure 9. Time history displacement of the structure controlled by an HMD using the IOC controller.

Figure 10 represents the force response required by the IOC to control the dynamic response. It appears that the order of magnitude of the control force is a thousand times smaller compared to those corresponding to the LQR and PID controllers.



Figure 10. Time evolution of the control force required by the IOC controller. 


\section{CONCLUSION}

In this work, the use of an hybrid mass damper for the analysis of the dynamic response and required control force of a wind tower model is studied. Three controllers are compared: LQR, PID and IOC. The analysis are performed using the wind turbine parameters model presented by S. Avila, M. Shzu, M. Morais et al. [2]. The results are obtained through numerical analysis considering dynamic excitations of wind and earthquake.

Although the LQR controller has a better response and a lower rms value than the PID, the two controllers reduce the system response satisfactorily. The IOC controller reduces the displacement of the system by up to 10 times and the force required to control the system is in the order of a thousand times less than the previous controllers.

It can be seen, therefore, that of the three controllers analyzed, the IOC was the one that presented the best performance, without adding computational effort. It even has the advantage of not relying on the solution of the Riccati problem, which can be computationally costly in the case of problems with a higher order. However, its efficiency is quite sensitive to the choice of suitable weighting matrices. For future work, it is interesting to carry out experimental studies using the Hardware in the Loop methodology to consolidate the comparative study.

Acknowledgements. The authors of this research are grateful for the financial support of the Coordination for the Improvement of Higher Education Personnel (CAPES) and the Post-Graduate Decanate of the University of Brasília (DPG-UnB).

Authorship statement. This section is mandatory and should be positioned immediately before the References section. The text should be exactly as follows: The authors hereby confirm that they are the sole liable persons responsible for the authorship of this work, and that all material that has been herein included as part of the present paper is either the property (and authorship) of the authors, or has the permission of the owners to be included here.

\section{REFERENCES}

[1] A. Pek, "A gust of growth in China makes 2020 a record year for wind energy," 2021. https://gwec.net/a-gust-of-growth-in-china-makes-2020-a-record-year-forwind-energy/ (accessed Feb. 20, 2021).

[2] S. M. Avila, M. A. M. Shzu, M. V. G. Morais, and Z. J. G. Del Prado, "Numerical modeling of the dynamic behavior of a wind turbine tower," J. Vib. Eng. Technol., vol. 4, no. 3, pp. 249-257, 2016.

[3] P. Liu and C. Y. Barlow, "Wind turbine blade waste in 2050," Waste Manag., vol. 62, no. February, pp. 229-240, 2017, doi: 10.1016/j.wasman.2017.02.007.

[4] T. T. Soong and G. F. Dargush, Passive energy dissipation systems in structural engineering. Chichester, 1997.

[5] A. S. Ahlawat and A. Ramaswamy, "Multi-objective optimal design of FLC driven hybrid mass damper for seismically excited structures," Earthq. Eng. Struct. Dyn., vol. 31, no. 7, pp. 1459-1479, 2002, doi: 10.1002/eqe.173. 
[6] V. Bhaiya, S. D. Bharti, M. K. Shrimali, and T. K. Datta, "Hybrid seismic control of buildings using tuned mass and magnetorheological dampers," Proc. Inst. Civ. Eng. Struct. Build., vol. 173, no. 7, pp. 471-487, 2018, doi:

10.1680/jstbu.18.00090.

[7] Y. Hu and E. He, "Active structural control of a floating wind turbine with a stroke-limited hybrid mass damper," J. Sound Vib., vol. 410, pp. 447-472, 2017, doi: 10.1016/j.jsv.2017.08.050.

[8] S. M. Avila, "Controle Híbrido para Atenuação de Vibrações em Edifícios," Pontífica Universidade Católica do Rio de Janeiro, 2002.

[9] G. B. Colherinhas, M. V. G. De Morais, M. A. M. Shzu, and S. M. Avila, "Optimal Pendulum Tuned Mass Damper Design Applied to High Towers Using Genetic Algorithms: Two-DOF Modeling,” Int. J. Struct. Stab. Dyn., vol. 19, no. 10, pp. 1-17, 2019, doi: 10.1142/S0219455419501256.

[10] S. Xie, X. Jin, J. He, J. Gao, C. Zhang, and Y. Yan, “Applying multiple tuned mass dampers to control structural loads of bottom-fixed offshore wind turbines with inclusion of soil-structure interaction," Ocean Eng., vol. 205, no. September 2018, p. 107289, 2020, doi: 10.1016/j.oceaneng.2020.107289.

[11] D. M. de Lima, P. A. López-Yánez, and M. A. Pereira, "Vibration control device for steel tubular towers of horizontal axis wind turbines," Lat. Am. J. Solids Struct., vol. 16, no. 6, pp. 1-21, 2019, doi: 10.1590/1679-78255436.

[12] M. Rahman, Z. C. Ong, W. T. Chong, S. Julai, and X. W. Ng, "Wind Turbine Tower Modeling and Vibration Control Under Different Types of Loads Using Ant Colony Optimized PID Controller," Arab. J. Sci. Eng., vol. 44, no. 2, pp. 707-720, 2019, doi: 10.1007/s13369-018-3190-6.

[13] A. Yanik, "Seismic control performance indices for magneto-rheological dampers considering simple soil-structure interaction," Soil Dyn. Earthq. Eng., vol. 129, no. November 2019, p. 105964, 2020, doi:

10.1016/j.soildyn.2019.105964.

[14] P. J. Murtagh, B. Basu, and B. M. Broderick, "Simple models for natural frequencies and mode shapes of towers supporting utilities," Comput. Struct., vol. 82, no. 20-21, pp. 1745-1750, 2004, doi: 10.1016/j.compstruc.2004.04.005.

[15] J. A. Guimarães, “Análise Dinâmica de Torre Eólica e Dimensionamento de Amortecedor de Massa Sintonizada," Instituto Politécnico de Bragança, 2020.

[16] P. H. Q. Rocha and S. M. Avila, "Vibration control of a wind turbine with a hybrid mass damper," Proc. Ibero-Latin-American Congr. Comput. Methods Eng., p. 6, 2020.

[17] M. Alves Melo, “Análise Comparativa de Estratégias para Suspensão Semiativa em um Modelo de 1/4 de Veículo," 2017.

[18] K. S. Park, H. M. Koh, and S. Y. Ok, "Active control of earthquake excited structures using fuzzy supervisory technique," Adv. Eng. Softw., vol. 33, no. 1112, pp. 761-768, 2002, doi: 10.1016/S0965-9978(02)00044-3.

[19] S. Etedali, M. R. Sohrabi, and S. Tavakoli, "An Independent Robust Modal PID Control Approach for Seismic Control of Buildings," J. Civ. Eng. Urban., vol. 3, no. 5, pp. 279-291, 2013. 
[20] J. C. Wu, J. N. Yang, and W. E. Schmitendorf, "Reduced-order Ho and LQR control for wind-excited tall buildings," Eng. Struct., vol. 20, no. 3, pp. 222-236, 1998, doi: 10.1016/S0141-0296(97)00081-3.

[21] L. Meirovitch, DYNAMICS AND CONTROL OF STRUCTURES, vol. 53, no. 9. New York, 1990.

[22] S. M. Avila and P. B. Gonçalves, "onderação Do Algoritmo De Controle Ótimo Para Um Amortecedor De Massa Híbrido ( Amh ),” vol. XXIX, pp. 15-18, 2010.

[23] A. K. Chopra, chopra, 4th ed., vol. 53, no. 9. California, 2012.

[24] J. P. DEN HARTOG, Mechanical Vibrations. New York, 1956. 